\title{
Taphonomy of a clypeasteroid echinoid using a new quasimetric approach
}

Tobias B. Grun and James H. Nebelsick

Acta Palaeontologica Polonica 61 (3), 2016: 689-699 doi:http://dx.doi.org/10.4202/app.00200.2015

A new quasimetric approach is used to statistically analyze taphonomic data from a commonly occurring shallow water clypeasteroid echinoid in order to obtain metric equivalent measurements of taphonomic alteration on an interval-like scale. This technique takes the character condition as well as its proportion into account and translates the taphonomic alteration into data, which behave as interval scaled and thus allows for the use of parametric as well as non-parametric statistics. Tests of Echinocyamus pusillus from Giglio Island (Mediterranean Sea, Italy) were analyzed with respect to a suite of taphonomic features including abrasion of the test surface, tubercles, ambulacral and genital pore margins as well as, if present, the outline and cross section of predatory drillholes. The degree of fragmentation and encrustation was also determined. Taphonomic features were analyzed using a semi-quantitative approach with three degrees of test alteration including non-altered, moderately altered, and highly altered which were statistically analyzed using non-parametric statistics due to highly non-normal distributed data. Abrasion intensities vary among different surface characters, with exposed areas of the test showing higher abrasion intensities than sheltered areas. Fragmentation occurs in low frequencies (7\%) and fractures in the tests are almost absent (1.7\%). Encrustation rates by bryozoans and serpulids can cover up to $80 \%$ of the test surface, but vary strongly among individuals and sample sites. Encrustation is independent of test size and prolongs overall test survival by crossing plate boundaries. The presence of drillholes in decreasing test preservation potentials is discussed with respect to analytical parameters.

Key words: Echinoidea, Echinocyamus, taphonomy, quasimetric, abrasion, encrustation, drillhole, Mediterranean.

Tobias B. Grun [tobias.grun@uni-tuebingen.de] and James H. Nebelsick [nebelsick@uni-tuebingen.de], Department of Geosciences, University of Tübingen, Sigwartstraße 10, D-72074 Tübingen, Germany.

This is an open-access article distributed under the terms of the Creative Commons Attribution License (for details please see creativecommons.org), which permits unrestricted use, distribution, and reproduction in any medium, provided the original author and source are credited. 
FoF 5 Full text $(771.9 \mathrm{kB})$ 